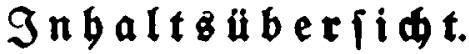

Cinleitumg. Bon Dr. jar. Alexander Elfter (Berlin) $\ldots \ldots \ldots \ldots \ldots \ldots$ IX

\section{Crfer Teil.}

Breis= und Sinsfentung. Bon RechtBanwalt Dr. Y $b_{0}$ olf Gollaender (Berlin) ........... 3

Berorbnung aber bic Befugniffe bes Reidstommiffars fít Bretsaberwađung. Bom 8. Dezember 1831 . . . 28

Grfte Durdfabrangs: unb Grgănjungsiveroronung aber Birsfentung auf bem sapttalmartt. Bom 23. Dezember

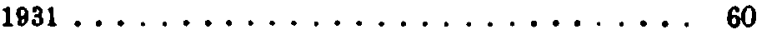

3 wetter xeil.

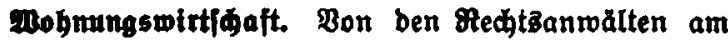
Rammergeriat Dr. $\mathcal{A r t b}$ ur $\mathfrak{B}$ Io \$ulvermader (Berlin) . . . . . . . . 73

Berorbnung zur Durdfâbrung ber Plettenlung. Bom

16. Dezember $1931 \ldots \ldots \ldots \ldots \ldots \ldots \ldots . \ldots 126$

Breubilie Berorbnung aber bie Mietientung. Bom

21. Dezember 1931; in ber fraffung vom 6. Januar 1932130

Berorbnung aber bie auberorbenttide priettanbtgung zum

5. Fanuar 1932. Bom 23. Dezember $1931 \ldots \ldots . .136$ 


\section{Dritter Reil.}

Geite

Rafmabmen auf Dem Gebiete der 3 wangswollftredung. Bon (Seridtsaffeffor Dr. Marl= \&uguft (5rifolli (BerIin)

\section{Bierter Teil.}

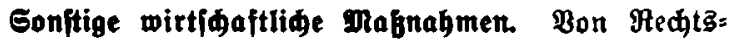
anralt $\mathfrak{x h e o d o r ~}$ geilborn (Berlin) .... 177

Berorbnung über cinmalige Bilanzierungøerlei

Bom 15. Dezenlber $1931 \ldots \ldots \ldots$

$$
\text { Fünfter } \mathfrak{T} \in \text { ill. }
$$

Sozialverifherung und Firiprge. Bon Direttor in

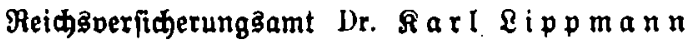
(Berlin) . . . . . . . . . . . . . . . 199

Seゆ) fter $\mathfrak{I} e$ il.

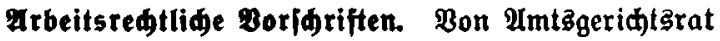

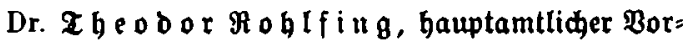
fïgendcr beim Urbeitg̈geriđt Berlin . . . . . . 231

Siebenter Teil.

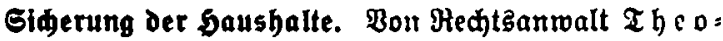
bor Deilborn (Berlin). . . . . . . 255

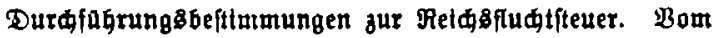
28. Dezcruer $1931 \ldots \ldots$. . . . . . . . . 290 
Inbaltouberfint.

A中ter xeil.

Gette

Squb des imeren Eriedens. Bon Beridtsaffeffor

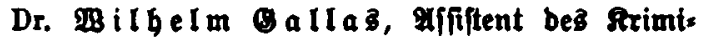

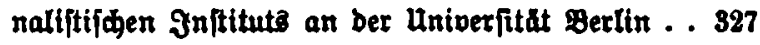

Reunter Ieil.

Sdubbeftimmung . . . . . . . . . . 351

Sadregifter ................. 352

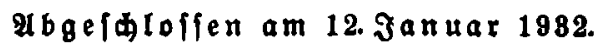

Bettere Dur由fabrungbeftimungen fino in ben

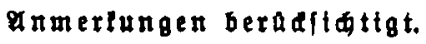


